This is an author produced version of a paper published in Brain Research Bulletin. This paper has been peer-reviewed but does not include the final publisher proof-corrections or journal pagination.

Citation for the published paper:

Anckarsater, Henrik.

"Central nervous changes in social dysfunction:

Autism, aggression, and psychopathy"

Brain Research Bulletin, 2006, Vol: 69, Issue: 3, pp. 259-65.

http://dx.doi.org/10.1016/j.brainresbull.2006.01.008

Access to the published version may require journal subscription.

Published with permission from: Elsevier 


\section{Central nervous changes in social dysfunction: autism, aggression, and psychopathy}

Henrik Anckarsäter, M.D., Ph.D.

Institute of Clinical Sciences, Malmö, Longitudinal Clinical Psychiatry, Lund University Malmö University Hospital, Forensic Psychiatric Clinic

Sege Park 8A, S-205 02 MALMÖ

E-mail: henrik.anckarsater@skane.se

Phone: +46-40-334031

Fax: $+46-40-334127$ 
Central nervous changes in social dysfunction: aggression, psychopathy, and autism 


\section{Abstract}

Neurodevelopmental disorders such as autism and schizophrenia involve social interaction problems and poor mentalizing abilities, associated with abnormal regional cerebral activity. Similar problems may be present in aggressive personality disorders and psychopathy. This paper reviews brain imaging data from research aiming at establishing possible central nervous correlates to aggression and psychopathy. Studies in this field are associated with a range of method problems. Differences between criminal offenders and controls may be confounded by a number of factors unrelated to personality traits or aggression per se. Phenotypical characterisation varies between studies as do the laboratory methods and their interpretation. In spite of these problems, there are some recurrent findings in the present literature. Hypoactivity or structural reduction of the prefrontal cortex is a consistent finding in violent offenders or subjects with antisocial personality disorder. When defined as a personality disorder of social interaction and empathy, psychopathy seems to be associated rather with central abnormalities in the limbic circuitry. Indications of an increased dopaminergic neurotransmission relative to the serotonergic have also been connected to such personality traits, especially to the $\mathrm{AD} / \mathrm{HD}$-related behavioural aspects. Further studies using strict phenotypical definitions or experimental models are clearly warranted to establish a pathophysiological background to destructive personality traits and the propensity to violent acting out.

Keywords: antisocial personality disorder, violence, neurotransmittor, brain imaging, empathy 


\section{Introduction: Social brain functioning}

Getting to know other people, responding to their behaviour, and developing insight into self and others by means of mutual reflections are essential processes in human life. These processes depend on neuropsychological abilities, such as the formation of a theory of mind (understanding that other people have inner mental lives) and mentalizing (attribution of intent and meaning to other people's behaviour), involving large parts of the brain. Social perception depends on vision and hearing, but also on sense of smell and somato-sensation, and on the associations with memories and emotions in the amygdala-hippocampal and other limbic structures. Social response formation involves automatic, stereotyped motor patterns encoded in brain stem nuclei and the hypothalamus as well as central limbic (including parts of the basal ganglia) and medial temporal structures, all in interplay with the frontal cortex, containing both posterior motor areas and the anterior, inhibitory and controlling parts. Also parts of the cerebellum and the corpus callosum, mediating the interplay between the hemispheres, are important for this "social brain". The verbal reasoning of the dominant hemisphere is balancing with the (often negative) emotionality of the non-dominant hemisphere. A wide array of neurotransmitter systems are involved in the functioning of these "social" circuits. The three monoaminergic systems, the serotonergic, originating in the raphe nuclei, the mesolimbic dopaminergic, originating in the substantia nigra, and the norepinephrinergic, originating in the locus coeruleus, project to and control the activity in vast areas of the brain. The GABAergic anti-excitatory system, the peptidergic systems (especially those using oxytocin and enkephalines), and neurons under the influence of steroid hormones are all of importance to social functioning (for overviews of the structure and functioning of the social brain, see 38, 49]. Extremely vast parts of the brain are thus involved in the exceptionally complex mental functions needed to guide social behaviour. 


\section{Social interaction disorders}

Autism and autism spectrum disorders have been used as prototypical social brain disorders as they are defined by early developmental aberrations in social interaction, in verbal as well as non-verbal communication, and in the ability to adjust one's own behaviour and thinking to other persons in a flexible way [83]. Autism has been linked to abnormal social brain functioning and neurological disorders [26]. Abnormalities in the perception of human faces and gazes are linked to a deficient or abnormal mentalizing ability in subjects with autism [7, $30,41]$. Recent data suggest that autism may represent an extreme dysfunction in abilities proposed to play an important role also in normal personality development $[68,15]$, abilities that are sometimes diminished also in relatives of persons with autism or in subjects with subsyndromal traits of the disorder $[23,25,12,8]$. The neurocognitive definitions of autism have, since their introduction during the 80ies, promoted a rapid growth of empirical research into the neurobiology and genetics of the disorder. Autism spectrum disorders and autistic traits are encountered in subgroups of violent offenders [71] and may be of relevance for the empathy problems encountered in personality disorders with troubled interpersonal interaction patterns $[65,72]$.

In the forensic field, disorders of social functioning are defined as antisocial personality disorder (defined mainly through behavioural criteria reflecting an early-onset pervasive pattern of norm-breaking) [3] or psychopathy (defined also by psychological criteria such as callousness, dominance-seeking, superficiality and affective blunting) [31]. Aggressive acts take place in a social context, where aberrations in perception, processing or reaction formation/control may be implicated, and violent offenders, without any further phenotype characterisation, have therefore been included in research on possible brain abnormalities. Psychopathy may be used as a more specific clinical phenotype, especially if the 
psychological, interpersonal, and affective deviances are focused upon to identify subjects with empathy problems [65].

Social interaction problems are also core features of a large number of mental disorders [25], including schizophrenia and personality disorders other than those related to criminality [3], and are also documented in important subgroups of persons suffering from anorexia nervosa [50], ADHD [39], and OCD [10].

Setting out from autism as an example of social interaction disorder, this paper will summarize current knowledge about social brain dysfunction in aggression, violent offending, and psychopathy.

\section{Social brain dysfunction in aggression and psychopathy}

Core abnormalities in the pathogenesis of autism are hypothetically located in the amygdala, adjacent limbic structures, and the corpus callosum [64, 47, 62, 26]. Damage to the amygdala is associated with impairments in social cognition and interpretation of emotions $[1,77]$, and the amygdala and the adjacent medial temporal lobes, hippocampi, and striatum show abnormalities in autism [5, 61]. Further down the CNS, abnormalities in the brain stem, where the nuclei of the monoaminergic systems and the cranial nerves are located, and in the cerebellum, are proposed to be relevant for autism [37,6]. The frontal cortex interplays with the limbic structures and plays a central role in the deviant processing of mentalizing documented in autism $[29,76]$. This research has firmly established autism as a social brain disorder, clinically well defined and also to a very high degree hereditary and/or associated with medical conditions affecting the social brain $[60,26]$. 
Studies of social brain dysfunction in aggression and psychopathy have not yet reached this clarity. Fundamental problems for research in this area lay in the definitions of index cases and controls. Studies have either focused on perpetrators of violent crimes, extremely aggressive subjects or personality traits thought to increase the risk of aggression, heterogeneously defined by psychological or behavioural criteria. Comparisons between neurobiological findings and behavioural patterns, in contrast, require highly specific characterisation of phenotypical traits and complicating factors mediating the risk for the targeted behaviour. Also the controls pose a major problem, as differences may be expected between criminal offenders or severely disabled patients and controls, who are often recruited among healthy hospital staff. Nor is it possible to draw conclusions about severely disturbed persons from correlations between brain functioning and behaviour in healthy controls - or vice versa. Subjects with severe social dysfunctions generally have complex mental problem constellations accompanied by troublesome life histories reducing the specificity of all neurobiological findings. The laboratory methods generally reflect indirect biological markers that may or may not be the expression of primary or secondary neurological events. And studies on aggressive behaviour are, for apparent reasons, performed first after the violent event, which further complicates the interpretation of findings.

The frontal lobes have been a primary target in the search for a substrate for aggression ever since the famous case report of Phineas Gage, who changed personality after a severe head injury to the frontal lobes [16], although the original case report states that Gage suffered from persistent infections, had surgery to remove a cerebral abscess, and suffered from untreatable seizures engaging the whole brain during his deterioration [33]. Studying regional brain glucose metabolism in murderers with PET, Raine and coworkers [54] found decreased activity in the prefrontal cortex in comparison to controls (see Table 1 for detailed 
information on studies in this area based on a MEDLINE search using the terms "tomography", "imaging", "viol*" and "aggr*"), and several other studies on offenders have documented frontal or temporal abnormalities in functioning or structure (Table 1). All these studies have been cross-sectional, and regional dysfunctions in perpetrators under the stress of a court procedure, awaiting harsh sentences, may express state rather than trait. In [38], Raine and coworkers published an important study documenting structural changes in the prefrontal lobes in community-recruited subjects with antisocial personality disorder. Psychopathy as a phenotype with a pervasively increased propensity for violent or damaging behaviour has been used to study pathophysiological mechanisms involved in these behaviours rather than using the behaviour per se as indicator. The evidence for frontal abnormalities specifically linked to psychopathy is not strong. In a recent volumetric MRI study [43], prefrontal volumes were uncorrelated to the total and factor scores of the PCL-R. MRI volumes, however, may not reflect functional activity, and in a SPECT study of PCL-R psychopathy, all correlations between the interpersonal Factor 1 and the frontal regions of interest were in the negative direction. Tests of executive functioning in psychopathy have shown normal results on attention shift tests such as the Wisconsin Card Sorting $[32,44]$ and on the intradimensional/extradimensional test (ID/ED) of attention shift, thought to largely represent the dorsolateral prefrontal functioning, while the response reversal facet of this test showed significant impairments, thought to reflect specifically the orbitofrontal functioning [48].

The central "social brain" areas seem to be more relevant than the frontal lobes for psychopathy. The function problems involved may be due to primary amygdala dysfunction $[11,80,75]$ or abnormal functioning in the limbic circuitry $[42,69]$. Recent functional MRI studies have shown that individuals with PCL-R-rated psychopathy have abnormal affective memory activation in the limbic system (cingulum, ventral striatum, amygdala/hippocampal 
formation, and parahippocampal gyri) and increased cortical activity in other frontotemporal areas [40], and that a similar group have deviant activation patterns in the right prefrontal areas, amygdala, subgenual cingulate and temporal gyrus, and in the left-sided dorsal cingulate and parahippocampal gyrus when shown negative affective pictures [49]. These findings support those from a previous SPECT study [36], indicating that subjects with psychopathic traits use non-limbic cognitive strategies to process affective words. Increased risk-taking, decreased learning from disadvantageous choices, and generally delayed responses in gambling tests, probably reflecting both frontal and amygdala abnormalities [9], complete this picture $[48,18]$. Remarkably few studies had challenged callosal functioning in psychopathy despite indications of specific verbal dysfunctions and intrahemispheric imbalance, but Raine and coworkers [59] have recently produced elegant documentation of correlations between abnormalities in the callosal area and psychopathy through fMRI and psychological tests.

In the background of psychopathy, childhood-onset neuropsychiatric disorders such as $\mathrm{AD} / \mathrm{HD}$ and learning disorders as well as early onset disruptive behaviour disorders may be discerned $[71,72]$. Boys with $\mathrm{AD} / \mathrm{HD}$ and conduct disorder also showed a decrement of autonomic responses and a more rapid habituation to orienting and adverse startling stimuli than boys with $\mathrm{AD} / \mathrm{HD}$ alone, thus resembling the profile described in adult psychopathy [34].

\section{Neurochemical correlates to social dysfunction}

The idea of a deficient behavioral inhibitory system and increased behavioral activation has been linked to the chemical activity of the central nervous monoamine systems (for overviews of these monoaminergic systems, see $38,73,17]$. Serotonergic projections from the raphe 
nuclei reach most parts of the brain and are thought to modulate other systems in the regulation of affect, appetite, fear, pain, aggression, mood, and impulse control. The mesolimbic dopaminergic system (projecting from the ventral tegmentum to limbic structures such as the amygdala, septal area, nucleus accumbens, and substantia innominata) is thought to stimulate emotional associations, mood, and reward, while the mesocortical dopaminergic projections are thought to underlie arousal and cognitive processes in the prefrontal cortex. The nigrostriatal dopaminergic system (from the substantia nigra to the striatal nuclei) is essential for motor functioning, but thought to be hyperactive in tics and stereotypies. The norepinephrinergic projections from the locus coeruleus are important for cognition, attention, motivation, emotional expression, and mood. Not only schizophrenia but also autism has been associated with an increased dopaminergic turn-over measured through the cerebrospinal fluid (CSF) concentration of its main metabolite, HVA [24]. These systems also play crucial roles in the regulation of aggression, where serotonin is thought to modulate and inhibit aggression driven by catecholamines. Serotonin activity, measured by its metabolite, 5-HIAA, in the CSF, has been consistently decreased in violent suicides [4] and destructive violence such as arson or the killing of a child or a sexual partner $[45,81]$ but not in outward-directed instrumental violence $[46,20,13,14]$. In these studies, also HVA has sometimes been decreased, but only as an absolute concentration, not in relation to the 5-HIAA concentration. In two subsequent study groups, we have registered associations between psychopathy (especially the behavioral aspects) and an increased HVA/5-HIAA ratio, indicating deficient serotonergic regulation of dopaminergic activity $[67,70]$. This ratio is more constant than each concentration per se [22]. An increased ratio may signal dopaminergic hyperactivity, but possibly also a reactive increase in signaling due to underactivity in prefrontal dopaminergic areas with hyposensitive or too few receptors, which has been proposed to play a role in $\mathrm{AD} / \mathrm{HD}$ and for negative symptoms in schizophrenia [73]. Further studies of transmitter 
systems involved in social brain dysfunction and empathy disorders may also consider neuropeptides (e.g. oxytocin, vasopressin, and endorphins) and neurosteroids (including the sex hormones).

\section{Discussion}

Across the heterogeneity of research methods and selection of subjects, it is apparent that the vast bulk of presented data describe hypoactivity or structural reduction of the prefrontal cortex in violent offenders or subjects with antisocial personality disorder. When defined as a personality disorder of social interaction and empathy, psychopathy seems to be associated rather with central abnormalities in the limbic circuitry. Mechanisms involved in emotional processing may be more important for psychopathy, while executive functions such impulse control may be of greater importance for unstructured, antisocial aggressive behaviour. Hypothetically, one common denominator behind these findings could be changes in the regulating balance of the monoaminergic transmitter systems, especially serotonin and dopamine. Further studies using strict phenotypical definitions or experimental models (such as activation studies of the amygdala) are clearly warranted to establish a pathophysiological background to destructive personality traits and the propensity to violent acting out.

Studies in this field are associated with a range of method problems. Differences between criminal offenders and controls may be confounded by a number of factors unrelated to personality traits or aggression per se. Phenotypical characterisation varies between studies as do the laboratory methods and their interpretation. There is a clear risk of publishing bias over-reporting positive findings. If a professional consensus on some basic assessment methods, ways of classifying aggressive behaviour, specific systems and functions to study and publishing practices could be introduced, the pay-off from future research in this field 
might be greatly enhanced without inferring costs for fund-givers or risks for research subjects. 


\section{References}

1. Adolphs R, Baron-Cohen S, Tranel D. Impaired recognition of social emotions following amygdala damage. J Cogn Neurosci 2002;14:1264-1274.

2. Amen DG, Stubblefield M, Carmichael B, Thisted R. Brain SPECT findings and aggressiveness. Ann Clin Psychiatry 1996;8:129-137.

3. American Psychiatric Association. Diagnostic and Statistical Manual of Mental Disorders - DSM-IV. Washington DC: American Psychiatric Association Press 1994.

4. Asberg M, Träskman L, Thorén P. 5-HIAA in the cerebrospinal fluid: a biochemical suicide predictor? Arch Gen Psychiatry 1976;33:1193-1197.

5. Aylward EH, Minshew NJ, Goldstein G, Honeycutt NA, Augustine A, Yates KO, Barta PE, Pearlson GD. MRI volumes of amygdala and hippocampus in non-mentally retarded autistic adolescents and adults. Neurology 1999;53:2145-2150.

6. Bailey A, Palferman S, Heavey L, Le Couteur A. Autism: the phenotype in relatives. $J$ Autism Dev Disord 1998;28:369-392.

7. Baron-Cohen S, Leslie A, Frith U. Does the autistic child have a "theory of mind"? Cognition 1985;21:37-46.

8. Baron-Cohen S, Bolton P, Wheelwright S, Short L, Mead G, Smith A, Scahill V. Autism occurs more often in families of physicists, engineers, and mathematicians. Autism 1998;2:296-301.

9. Bechara A, Damasio H, Damasio AR, Lee GP. Different contributions of the human amygdala and ventromedial prefrontal cortex to decision-making. J Neurosci 1999;19:5473-5481.

10. Bejerot S, Nylander L, Lindström E. Autistic traits in obsessive-compulsive disorders. Nordic J Psychiatry 2001;55:169-176. 
11. Blair RJ, Frith U. Neurocognitive explanations of the antisocial personality disorders. Crim Behav Ment Health 2000;10: 66-82.

12. Briskman J, Happé F, Frith U. Exploring the cognitive phenotype of autism: Weak "central coherence" in parents and siblings of children with autism: II. Real-life skills and preferences. J Child Psychol Psychiatry 2001;42:309-316.

13. Castellanos FX, Elia J, Kruesi MJ, Gulotta CS, Mefford IN, Potter WZ, Ritchie GF, Rapoport JL. Cerebrospinal fluid monoamine metabolites in boys with attention-deficit hyperactivity disorder. Psychiatry Res 1994;52:305-316.

14. Coccaro EF, Kavoussi RJ, Cooper TB, Hauger RL. Central serotonin activity and aggression: inverse relationship with prolactin response to d-fenfluramine, but not CSF 5HIAA concentration, in human subjects. Am J Psychiatry 1997:154:1430-1435.

15. Constantino JN, Todd RD. Autistic traits in the general population: a twin study. Arch Gen Psychiatry 2003;60:524-530.

16. Damasio H, Grabowski T, Frank R, Galaburda AM, Damasio AR. The return of Phineas Gage: clues about the brain from the skull of a famous patient. Science 1994;264:11021105.

17. Deutch AY, Roth RH. Neurochemical systems in the central nervous system. In: Charney DS et al. (eds.): Neurobiology of mental illness. New York, Oxford: Oxford University Press 2001, pp. 10-26.

18. Flor H, Birbaumer N, Hermann C, Ziegler S, Patrick CJ. Aversive Pavlovian conditioning in psychopaths: perpheral and central correlates. Psychophysiology 2002;39:505-518.

19. Frankle WG, Lombardo I, New AS, Goodman M, Talbot PS, Huang Y, Hwang DR, Slifstein M, Curry S, Abi-Dargham A, Laruelle M, Siever LJ. Brain serotonin transporter distribution in subjects with impulsive aggressivity: a positron emission study with (11C) McN5652. Am J Psychiatry. 2005:162(5):915-23. 
20. Gardner DL, Lucas PB, Cowdry RW. CSF metabolites in borderline personality disorder compared with normal controls. Biol Psychiatry 1990;28:247-254.

21. George DT, Rawling RR, Williams WA, Phillips MJ, Fong G, Kerich M, Momenan R, Umhau JC, Hommer D. A select group of perpetrators of domestic violence: evidence of decreased metabolism in the right hypothalamus and reduced relationships between cortical/subcortical brain structures in position emission tomography. Psychiatry Res. $2004 ; 15 ; 130: 11-25$

22. Geracioti TD Jr, Keck PE, Ekhator NN, West SA, Baker DG, Hill KK, Bruce AB, Wortman MD. Continuous covariability of dopamine and serotonin metabolites in human cerebrospinal fluid. Biol Psychiatry 1998;44:228-233.

23. Gillberg C. Autism and autistic-like conditions: subclasses among disorders of empathy. $J$ Child Psychol Psychiatry 1992;33:813-842.

24. Gillberg C, Svennerholm L, Hamilton-Hellberg C. Childhood psychosis and monoamine metabolites in spinal fluid. J Autism Dev Disord 1983;13:383-396.

25. Gillberg C, Gillberg IC, Steffenburg S. Siblings and parents of children with autism: a controlled population-based study. Dev Med Child Neurol 1992;34:389-398.

26. Gillberg C, Coleman M. The biology of the autistic syndromes. $3^{\text {rd }}$ Ed. London: Cambridge University Press; 2000.

27. Goyer PF, Andreason PJ, Semple WE, Clayton AH, King AC, Comton-Toth BA, Schulz SC, Cohen RM. Positron-emission tomography and personality disorders. Neuropsychopharmacol 1994;10:21-28.

28. Goyer PF, Semple W. Pet studies of aggression in personality disorder and other nonpsychotic patients. In: Stoff DM, Cairns RB (eds.): Aggression and violence: Genetic, neurobiological, and biosocial perspectives. Mahwah: Lawrence Erlbaum Associates Inc 1996, pp. 219-235. 
29. Happé F, Ehlers S, Fletcher P, Frith U, Johansson M, Gillberg C, Dolan R, Frackowiak R, Frith C. "Theory of mind" in the brain. Evidence from a PET scan study of Asperger syndrome. Neuroreport 1996;8:197-201.

30. Happé F, Briskman J. Exploring the cognitive phenotype of autism: weak "central coherence" in parents and siblings of children with autism: I. Experimental tests. J Child Psychol Psychiatr 2001;42:299-307.

31. Hare RD. A research scale for the assessment of psychopathy in criminal populations. Pers Indiv Differ 1980;1:111-119.

32. Hare RD. Performance of psychopaths on cognitive tasks related to frontal lobe function. J Abnorm Psychol 1984;93:133-140.

33. Harlow JM. Passage of an iron bar through the head. Mass Med Soc Pub 1869;2:327-346.

34. Herpertz SC, Wenning B, Mueller B, Quinaibi M, Sass H, Herpertz-Dahlman B. Psychophysiological responses in ADHD boys with and without conduct disorder. Implications for adult antisocial behavior. J Am Acad Child Adolesc Psychiatry 2001;40:1222-1230.

35. Hoptman MJ, Volavka J, Johnson G, Weiss E, Bilder RM, Lim KO. Frontal white matter microstructure, aggression, and impulsivity in men with schizophrenia: a preliminary study. Biol Psychiatry 2002;52:9-14.

36. Intrator J, Hare R, Stritzke P, Brichtswein K, Dorfman D, Harpur T, Bernstein D, Handelsman L, Schafer C, Keilp J, Rosen J, Machac J. A brain imaging (single photon emission computerized tomography) study of semantic and affective processing in psychopaths. Biol Psychiatry 1997;42:96-103.

37. Johansson M, Wentz E, Fernell E, Stromland K, Miller MT, Gillberg C. Autistic spectrum disorders in Mobius sequence: a comprehensive study of 25 individuals. Dev Med Child Neurol 2001;43:338-345. 
38. Joseph R. Neuropsychiatry, neuropsychology, and clinical neuroscience. Baltimore MA: Williams \& Wilkins 1996.

39. Kadesjo B, Gillberg C. The comorbidity of ADHD in the general population of Swedish school-age children. Child Psychol Psychiatry 2001;42:487-492.

40. Kiehl KA, Smit AM, Hare RD, Mendrek A, Forster BB, Brink J, Liddle PF. Limibic abnormalities in affective processing by criminal psychopaths as revealed by functional magnetic resonance imaging. Biol Psychiatry 2001;50:677-684.

41. Klin A, Jones W, Schultz R, Volkmar F, Cohen D. Defining and quantifying the social phenotype in autism. Am J Psychiatry 2002;159:895-908.

42. Laakso MP, Vaurio O, Koivisto E, Savolainen L, Eronen M, Aronen HJ, Hakola P, Repo E, Soininen H, Tiihonen J. Psychopathy and the posterior hippocampus. Behav Brain Res 2001;118:187-193.

43. Laakso MP, Gunning-Dixon F, Vaurio O, Repo-Tiihonen E, Soininen H, Tiihonen J. Prefrontal volumes in habitually violent subjects with antisocial personality disorder and type 2 alcoholism. Psychiatry Res Neuroimaging 2002;114:95-102.

44. LaPierre D, Braun CMJ, Hodgins S. Ventral frontal deficits in psychopathy: Neuropsycho-logical test findings. Neuropsychologica 1995;33:139-151.

45. Lidberg L, Asberg M, Sundqvist-Stensman UB. 5-hydroxyindoleacetic acid levels in attempted suicides who have killed their children. Lancet 1984:2(8408):928.

46. Lidberg L, Tuck JR, Asberg M, Scalia-Tomba GP, Bertilsson L. Homicide, suicide and CSF 5-HIAA. Acta Psychiatr Scand 1985;71:230-236.

47. Manes F, Piven J, Vrancic D, Nanclares V, Plebst C, Starkstein SE. An MRI of the corpus callosum and cerebellum in mentally retarded autistic individuals. J Neuropsychiatry Clin Neurosci 1999;11:470-474. 
48. Mitchell DG, Colledge E, Leonard A, Blair RJ. Risky decisions and response reversal: is there evidence of orbitofrontal cortex dysfunction in psychopathic individuals? Neuropsychologia 2002;40:2013-2022.

49. Müller J, Sommer M, Wagner V, Lange K, Taschler H, Röder CH Schuierer G, Klein HE, Hajak G. Abnormalities in emotion processing within cortical and subcortical regions in criminal psychopaths: evidence from a functional magnetic resonance imaging study using pictures with emotional content. Biol Psychiatry 2003;54:152-162.

50. Nilsson EW, Gillberg C, Gillberg IC, Rastam M. Ten-year follow-up of adolescent-onset anorexia nervosa: personality disorders. J Am Acad Child Adolesc Psychiatry $1999 ; 38: 1389-1395$.

51. Oder W, Goldenberg G, Spatt J, Podreka I, Binder H, Deecke L. Behavioural and psychosocial sequelae of severe closed head injury and regional cerebral blood flow: a SPECT study. J Neurol Neurosurg Psychiatry 1992;55: 475-480.

52. Parsey RV, Oquendo MA, Simpson NR, Ogden RT, Van Heertum R, Arango V, Mann JJ. Effects of sex, age, and aggressive traits in man on brain serotonin $5-\mathrm{HT}_{1 \mathrm{~A}}$ receptor binding potential measured by PET using [C-11]WAY-100635. Brain Res 2002;954:173182.

53. Pietrini P, Guazzelli M, Basso G, Jaffe K, Grafman J. Neural correlates of imaginal aggressive behaviour assessed by positron emission tomography in healthy subjects. Am J Psychiatry 2000;157:1772-1781.

54. Raine A, Buchsbaum MS, Stanley J, Lottenberg S, Abel L, Stoddard J. Selective reductions in prefrontal glucose metabolism in murderers. Biol Psychiatry 1994;36:365373.

55. Raine A, Buchsbaum M, LaCasse L. Brain abnormalities in murderers indicated by positron emission tomography. Biol Psychiatry 1997;42:495-508. 
56. Raine A, Phil D, Stoddard J, Bihrle S, Buchsbaum M. Prefrontal glucose deficits in murderers lacking psychosocial deprivation. Neuropsychiatry Neuropsychol Behav Neurol 1998a;11:1-7.

57. Raine A, Meloy JR, Bihrle S, Stoddard J, LaCasse L, Buchsbaum MS. Reduced prefrontal and increased subcortical brain functioning assessed using positron emission tomography in predatory and affective murderers. Behav Sci Law 1998b;16:319-332.

58. Raine A, Lencz T, Bihrle S, LaCasse L, Colletti P. Reduced prefrontal gray matter volume and reduced autonomic activity in antisocial personality disorder. Arch Gen Psychiatry 2000;57:119-127.

59. Raine A, Lencz T, Taylor K, Hellige JB, Bihrle S, Lacasse L, Lee M, Ishikawa S, Colletti P. Corpus callosum abnormalities in psychopathic antisocial individuals. Arch Gen Psychiatry 2003;60:1134-1142.

60. Rutter M, Silberg J, O’Connor T, Simonoff E. Genetics and child psychiatry: II Empirical research findings. J Child Psychol Psychiatry 1999;40:19-55.

61. Ryu YH, Lee JD, Yoon PH, Kim DI, Lee HB, Shin VJ. Perfusion impairments in infantile autism on technetium-99m ethyl cysteinate dimer brain single-photon emission tomography: comparison with findings on magnetic resonance imaging. Eur J Nucl Med $1999 ; 26 ; 253-259$.

62. Sears LL, Vest C, Mohamed S, Bailey J, Ranson BJ, Piven J. An MRI study of the basal ganglia in autism. Prog Neuropsychopharmacol Biol Psychiatry 1999;23:613-624.

63. Seidenwurm D, Pounds TR, Globus A, Valk PE. Abnormal temporal lobe metabolism in violent subjects: correlation of imaging and neuropsychiatric findings. Am J Neuroradiol 1997;18:625-631. 
64. Semrud-Clikeman M, Hooper SR, Hynd GW, Hern K, Presley R, Watson T. Prediction of group membership in developmental dyslexia, attention deficit hyperactivity disorder, and normal controls using brain morphometric analysis of magnetic resonance imaging. Arch Clin Neuropsychol 1996;11:521-528.

65. Soderstrom H. Psychopathy as a disorder of empathy. Eur J Child Adolesc Psychiatry $2003 ; 12: 249-252$.

66. Soderstrom H, Tullberg M, Wikkelso C, Ekholm S, Forsman A. Reduced regional cerebral blood flow in non-psychotic violent offender. Psychiatry Res Neuroimaging 2000;98:29-41.

67. Soderstrom H, Blennow K, Manhem A, Forsman A. CSF studies in violent offenders. I. 5HIAA as a negative and HVA as a positive predictor of psychopathy. $J$ Neural Transm 2001;108:869-878.

68. Soderstrom H, Rastam M, Gillberg C. Temperament and character in adults with Asperger syndrome. Autism 2002a;6:287-297.

69. Soderstrom H, Hultin L, Tullberg M, Wikkelsö C, Ekholm S, Forsman A. Reduced frontotemporal cerebral blood flow in psychopathic personality. Psychiatry Res Neuroimaging 2002b;114:81-94.

70. Soderstrom H, Blennow K, Sjodin A-K, Forsman A. New evidence for an association between the CSF HVA/5-HIAA ratio and psychopathy. J Neurol Neurosurg Psychiatry 2003;74:918-921.

71. Soderstrom H, Sjodin AK, Carlstedt A, Forsman A. Adult psychopathic personality with childhood-onset hyperactivity and conduct disorder: a central problem constellation in forensic psychiatry. Psychiatry Res 2004;121:271-280. 
72. Soderstrom H, Nilsson T, Sjodin AK, Carlstedt A, Forsman A. The childhood-onset neuropsychiatric background to adulthood psychopathic traits and personality disorders. Compr Psych 2005:46:111-6.

73. Stahl SM. Placebo-controlled comparison of the selective serotonin reuptake inhibitors citalopram and seratraline. Biol Psychiatry 2000;48:894-901.

74. Sterzer P, Stadler C, Krebs A, Kleinschmidt A, Poustka F. Abnormal neural responses to emotional visual stimuli in adolescents with conduct disorder. Biol Psychiatry $2005 ; 1 ; 57: 7-15$.

75. Stevens D, Charman T, Blair RJ. Recognition of emotion in facial expressions and vocal tones in children with psychopathic tendencies. J Genet Psychol 2001;162:201-211.

76. Stone VE, Baron-Cohen S, Knight RT. Frontal lobe contributions to theory of mind. $J$ Cogn Neurosci 1998;10:640-56

77. Stone VE, Baron-Cohen S, Calder A, Keane J, Young A. Acquired theory of mind impairments in individuals with bilateral amygdala lesions. Neuropsychologia 2003;41:209-220.

78. Tiihonen J, Kuikka J, Bergström K, Hakola P, Karhu J, Ryynänen OP, Föhr J. Altered striatal dopamine re-uptake site densities in habitually violent and non-violent alcoholics. Nature Med 1995;1:654-657.

79. Tiihonen J, Kuikka JT, Bergstrom KA, Karhu J, Viinamaki H, Lehtonen J, Hallikainen T, Yang J, Hakola. Single-photon emission tomography imaging of monoamine transporters in impulsive violent behaviour. Eur J Nucl Med 1997;24:1253-1260.

80. Tiihonen J, Hodgins S, Vaurio O, Laakso M, Repo E, Soininen H, Aronen HJ, Nierminen P, Savolainen L. Amygdaloid volume loss in psychopathy. Soc Neurosci Abstracts 2000; p 2017. 
81. Virkkunen M, Rawlings R, Tokola R, Poland RE, Guidotti A, Nemeroff C, Bissette G. Kalogeras K, Karonen SL, Linnoila M. CFS biochemistries, glucose metabolism, and diurnal activity rhythms in alcoholic, violent offenders, fire setters, and healthy volunteers. Arch Gen Psychiatry 1994:51:20-27.

82. Volkow N, Tancredi L. Neural substrates of violent behaviour. A preliminary study with positron emission tomography. Br J Psychiatry 1987;151:668-673.

83. Wing L. Language, social, and cognitive impairments in autism and severe mental retardation. J Autism Dev Disord 1981;11:31-44.

84. Wong MT, Lumsden J, Fenton GW, Fenwick PB. Electroencephalography, computed tomography and violence ratings of male patients in a maximum security mental hospital. Acta Psychiatr Scand 1994;90:97-101.

85. Wong M, Fenwick P, Fenton G, Lumsden J, Maisey M, Stevens J. Repetitive and nonrepetitive violent behaviour in male patients in a maximum security mental hospital clinical and neuroimaging findings. Med Sci Law 1997a;37:150-160.

86. Wong MT, Fenwick PB, Lumsden J, Fenton GW, Maisey MN, Lewis P, Badawi R. Positron emission tomography in male violent offenders with schizophrenia. Psychiatry Res 1997b;68:111-123. 
Table 1. Studies on regional cerebral activity in aggression and psychopathy

\begin{tabular}{|c|c|c|}
\hline Publication & $\begin{array}{l}\text { Imaging } \\
\text { technique }\end{array}$ & Study population and Main findings \\
\hline $\begin{array}{l}\text { Amen et al., } \\
1996[2]\end{array}$ & $\begin{array}{l}\text { SPECT } \\
\left({ }^{99} \mathrm{Tc}-\right. \\
\text { HMPAO) }\end{array}$ & $\begin{array}{l}40 \text { aggressive patients showed decreased activity in the prefrontal cortex, } \\
\text { increased activity in antero-medial frontal regions and the basal ganglia and/or } \\
\text { limbic system, and focal abnormalities in the left temporal lobe in comparison to } \\
40 \text { non-aggressive psychiatric patients. }\end{array}$ \\
\hline $\begin{array}{l}\text { Frankle et al., } \\
2005[19]\end{array}$ & $\begin{array}{l}\text { PET } \\
{[(11) \mathrm{C}] \mathrm{McN}} \\
5652\end{array}$ & $\begin{array}{l}\text { Serotonin transporter availability was significantly reduced in the anterior } \\
\text { cingulated cortes of } 10 \text { individuals withimpulsive aggression compared to } 10 \\
\text { healthy controls. }\end{array}$ \\
\hline $\begin{array}{l}\text { George et al., } \\
2004[21]\end{array}$ & $\begin{array}{l}\text { PET } \\
\left({ }^{18} \mathrm{FDG}\right)\end{array}$ & $\begin{array}{l}\text { Significantly lower mean glucose uptake in the right hypothalamus in } 8 \text { subjects } \\
\text { with alcoholism and a history of domestic violence compared to } 11 \text { subjects with } \\
\text { alcoholism and } 10 \text { healthy controls. }\end{array}$ \\
\hline Goyer et al., & PET & 17 patients with personality disorders had a significant inverse correlation \\
\hline 1994 [27] & $\left({ }^{18} \mathrm{FDG}\right)$ & $\begin{array}{l}\text { between life histories of aggression and regional metabolism in a frontal } \\
\text { transaxial region, and those with borderline personality disorder had significant }\end{array}$ \\
\hline Goyer and & & changes frontally as compared to 43 normal controls (1994). The association \\
\hline Semple, 1996 & & between regional frontal metabolism and aggressive impulse problem was \\
\hline$[28]$ & & supported by an extension of the study to 10 patients with PTSD (1996). \\
\hline $\begin{array}{l}\text { Hoptman et } \\
\text { al., } 2002[35]\end{array}$ & MRI & $\begin{array}{l}\text { In } 14 \text { men with schizophrenia, aggression was associated with changes in } \\
\text { inferior frontal white matter microstructure measured by diffusion tensor } \\
\text { imaging (DTI). }\end{array}$ \\
\hline Intrator et al., & SPECT & 8 psychopaths, 9 non-psychopaths, 9 controls. Psychopaths showed bilateral \\
\hline $1997[36]$ & $\begin{array}{l}\left({ }^{99} \mathrm{Tc}-\right. \\
\text { HMPAO) }\end{array}$ & $\begin{array}{l}\text { frontotemporal hyperactivation for emotional words on a lexical decision task } \\
\text { neutral vs. emotional words }\end{array}$ \\
\hline
\end{tabular}

Kiehl et al., $\quad$ fMRI $\quad 8$ criminal psychopaths, 8 criminal nonpsychopaths, 8 general population $2001[40]$ controls. Psychopaths showed significantly less affect-related activity in the amygdala/hippocampal formation, parahippocampal gyrus, ventral striatum, and in the anterior and posterior cingulate gyri, in combination with over-activity in 
the frontotemporal cortices in an affective memory task.

Laakso et al., $\quad$ MRI 18 violent alcoholic offenders. Negative correlations between psychopathy ratings and the posterior hippocampus volume

Laakso et al., $\quad$ MRI 24 violent males, 33 controls. Education- and alcohol-related reductions of $2002[43]$ prefrontal cortex but no association with psychopathy

Müller et al.,

fMRI 6 male psychopaths, 6 controls. Affective pictures with negative content $2003[49]$

Oder et al., SPECT increased activation in the right prefrontal region and the amygdala and reduced activation in the left dorsal cingulate and the parahippocampal gyrus.

$1992[51]$ ${ }^{99} \mathrm{Tc}-$ 36 patients who had suffered closed head injuries about 40 months before the

HMPAO) frontal hypoperfusion, 2) aggression and right hemisphere hypoperfusion, and 3)

Parsey et al., PET social isolation and left hemisphere hypoperfusion.

$2002[52]$

([C- $\quad 5-\mathrm{HT}_{1 \mathrm{~A}}$ binding and aggression in the anterior cingulate, amygdala, dorsal raphe,

11]WAY- and prefrontal cortex.

$100635)$

Pietrini et al., PET 15 healthy subjects imagined neutral and aggressive scenarios. Significant $2000[53]$ $\left({ }^{15} \mathrm{OH}_{2} \mathrm{O}\right)$ decreases in the medial orbitofrontal cortex compared to the neutral condition.

Raine et al., PET $1994[54]$

Raine et al., $1997[55]$

Raine et al., $1998 \mathrm{a}[56]$

Raine et al., $1998 b[57]$ groups were extended to 41 subjects. Notes on early psychosocial deprivation were used for comparisons within the index group in 1998a, and 15 predatory murderers were compared to 9 affective murderers in $1998 \mathrm{~b}$. Index cases showed significant reduction of prefrontal glucose metabolism, particularly on the left side in the 1994 study. In the larger 1997 sample, reduced metabolism could be demonstrated in the prefrontal cortex, superior parietal gyrus, left angular gyrus, and the corpus callosum. The prefrontal hypometabolism was more severe in the index cases without early psychosocial 


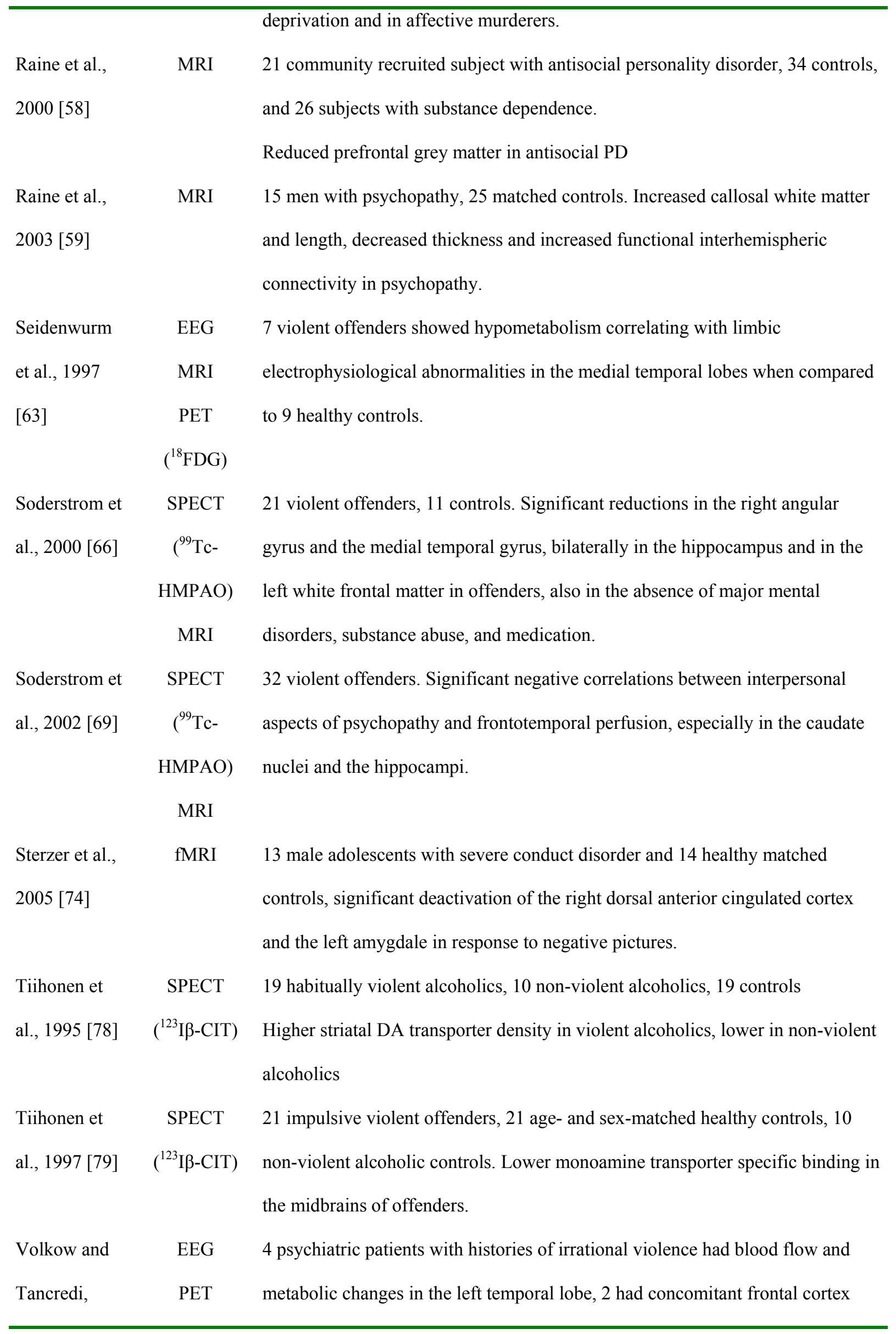




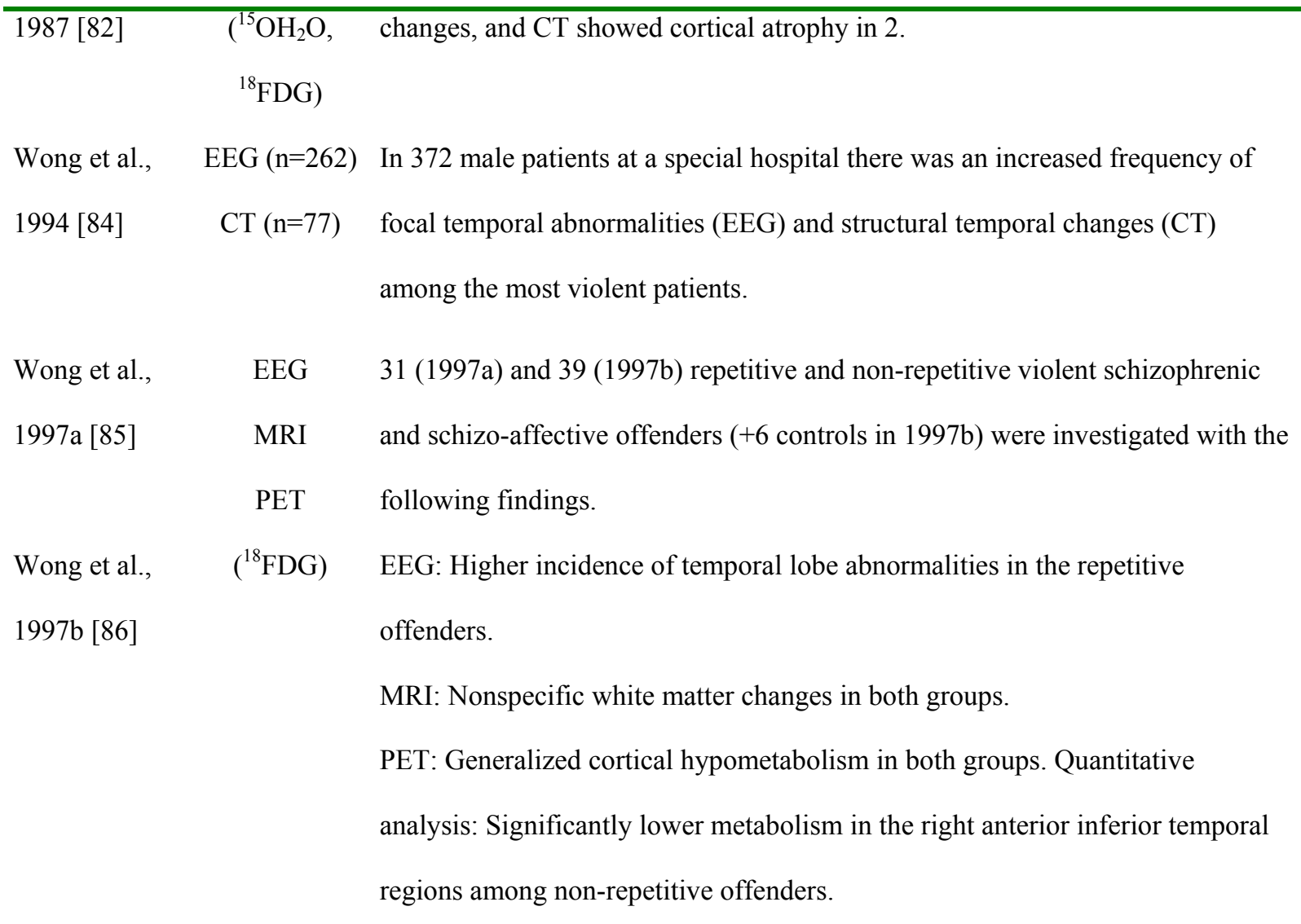

